\title{
La memoria histórica en España y su situación en el ámbito educativo: la necesidad de crear un museo memorial en España
}

\section{Historical Memory in Spain and its present situation in the educational field: the necessity of creating a memorial museum in Spain}

\author{
MANUEL BARREIRO MARIÑO \\ Universidad Autónoma de Madrid \\ manolobarreirojr@gmail.com
}

\begin{abstract}
Resumen: 80 años después del inicio de la Guerra Civil española es momento de echar la vista atrás para conocer cuánto sabemos de nuestro pasado reciente y cuál es el tratamiento y presencia que dicho pasado tiene en nuestro presente. Para ello debemos compararlo con otros países que también hayan sufrido un pasado traumático y así poder entender porque la situación de la memoria histórica en España cuarenta años después del fin de la dictadura sigue siendo prácticamente inexistente. A través de esta comparación comprenderemos que la labor educativa en España en cuanto a la enseñanza de los hechos ocurridos durante la Guerra Civil y la dictadura de Franco ha sido totalmente deficiente al mostrarse un gran desconocimiento general por parte de la sociedad española. Partiendo de otros procesos de revisión del pasado como Alemania, Argentina o Chile, entenderemos la necesidad urgente de crear un museo memorial en España.
\end{abstract}

Palabras clave: Memoria histórica, España, museo memorial.

\begin{abstract}
Eighty years after the beginning of the Spanish Civil War it is the time to look back for knowing how much we have learnt about our recent past, how it is being dealt with and how present it is in our lives. To do this, we should compare our past with other countries which have also undergone a traumatic past; in this way we will be able to understand why the historical memory in Spain is practically non-existent. This comparison allows us to understand that the educational task in Spain concerning the teaching of the facts during the Civil War and Franco's dictatorship has been totally insufficient and the unawareness of the Spanish society regarding this matter is huge. On the basis of other political processes like the ones occurred in Germany, Argentina or Chile, we can understand the necessity of creating a memorial museum in Spain.
\end{abstract}

Keywords: Historical memory, Spain, memorial museum.

Recibido: 22 de noviembre de 2016; aceptado: 18 de febrero de 2017; publicado: 21 de septiembre de 2017. Revista Historia Autónoma, 11 (2017), pp. 261-278.

e-ISSN: 2254-8726; DOI: https://doi.org/10.15366/rha2017.11.013 


\section{Situación actual de la Memoria Histórica en España}

En el año 2016 se cumple el 80 aniversario del comienzo de la Guerra Civil española, 18 de julio de 1936. Dicha contienda enfrentó al bando sublevado, organizado en torno a una importante parte del alto mando militar e integrado, fundamentalmente, por miembros de la Falange, por partidarios del Carlismo y adeptos a la CEDA (Confederación Española de Derechas Autónomas, frente político de ideología conservadora que existió durante la Segunda República); con el bando republicano, establecido en torno al gobierno de la República que dirigía el Frente Popular; y que terminó con la posterior derrota de este último bando y el consecuente fin del sistema democrático en España en 1939.

El cumplimiento de los 80 años del inicio de este conflicto bélico ha desencadenado la celebración de numerosos actos a lo largo del territorio español de carácter tanto conmemorativo como científico, principalmente desde el ámbito académico, tales como el "IX Encuentro de Investigadores del Franquismo: 80 años de la Guerra Civil”, organizado por la Universidad de Granada, el Congreso Internacional "1936. Un novo relato? 80 anos entre historia e memoria", coordinado por el grupo de Investigación Histagra y por la Universidad de Santiago de Compostela, o la "Sortida Cultural I Conmemorativa", llevada a cabo por el Ayuntamiento de Girona, entre otros muchos actos. No obstante, a pesar de los constantes esfuerzos impulsados por parte de numerosas universidades españolas y otras asociaciones de carácter cultural y/o político, en materia de recuperación de la memoria histórica podemos afirmar con contundencia que en España, 80 años después del comienzo de la Guerra Civil, el desenvolvimiento en dicha recuperación a día de hoy es claramente deficiente.

Es significativo de la pobre situación de la recuperación de la memoria histórica en España el informe ${ }^{1}$ publicado por la ONU (Organización de Naciones Unidas) en el año 2014, en el cual se analizaba la labor desarrollada por el gobierno español a favor de la reparación de los crímenes contra los Derechos Humanos cometidos durante la guerra y durante la dictadura franquista y en el cual se destacaba el escaso trabajo realizado en favor de esta tarea. La ONU hizo así recuento de los diferentes apartados del ámbito político y cultural que el gobierno español debe modificar si pretende reparar legalmente y compensar por los daños sufridos entre el inicio de la Guerra Civil y el fin de la dictadura de Franco, destacando entre ellos: la aún notoria existencia de calles, edificios e insignias que ensalzan la figura de altos representantes del franquismo; la presencia de un currículo educativo en la enseñanza obligatoria que carece de rigor histórico y que invita al olvido de lo sucedido; la falta de apoyo económico a las familias en las tareas de exhumación de los restos de sus familiares muertos durante la Guerra

${ }^{1}$ Chientaroli, Natalia, "Los 10 suspensos de la ONU a España en memoria histórica". en eldiario.es, 28 de agosto de 2014. «http://www.eldiario.es/sociedad/ONU-Espana-Guerra-Civil-franquismo_0_297120710.html» [consultado el 3 de marzo de 2016]. 
Civil y el franquismo; y el uso como obstáculo para la apertura de investigaciones sobre esa época de la Ley de Amnistía de $1977^{2}$, lo que contradice a los acuerdos firmados por España en el ámbito internacional a favor del cumplimiento de los Derechos Humanos, véase Convenio Europeo para la Protección de Derechos Humanos y de las Libertades Fundamentales ${ }^{3}$, firmado en 1979. En la misma línea que la ONU, Amnistía Internacional critica la inactividad del gobierno español a la hora de intentar reparar "la deuda pendiente con las víctimas de la guerra civil y el franquismo"4. De esta manera, los dictámenes de la ONU y Amnistía Internacional son representativos de que aún es mucha la labor que hay en materia de memoria histórica en España por desarrollar, siendo claramente insuficiente lo hecho hasta ahora. No obstante, no todo es negativo en el ámbito de la memoria histórica, la aprobación de la Ley de la Memoria Histórica en $2007^{5}$, aunque ignorada hoy en día por el gobierno actual, ayudó a asentar las bases del movimiento social existente a favor de la recuperación de la memoria y comenzó a reparar económicamente a las víctimas del franquismo. A pesar de ello, esta ley muestra importantes carencias tales como la no anulación de los Juicios Sumarios dictados durante el franquismo o el no reconocimiento de la Segunda República como gobierno legalmente constituido; por otro lado, desde 2014 algunos gobiernos locales de ciudades como A Coruña, Madrid o Pamplona, entre otras, han comenzado a retirar de sus calles toda aquella simbología perteneciente al franquismo y a homenajear a todas aquellas personas caídas en la guerra civil en defensa de la democracia. Dicho esto, no podemos obviar sentencias tales como las de la ONU que nos muestran el porqué de la deficiente situación de la recuperación de nuestro pasado reciente más traumático.

La falta de un proceso en profundidad de recuperación del pasado reciente impulsado por el gobierno español tiene su origen en el relato sobre el que se ha ido asentando nuestra democracia y que sostiene el régimen político actual y sus instituciones; un relato fundamentado en la idea de evitar "reabrir viejas heridas". El triunfo de dicho relato trajo consigo el miedo por parte de la sociedad a una nueva repetición de la Guerra Civil, la fuerte presencia de altos cargos procedentes de la dictadura y la consecuente Ley de Amnistía de 1977, lo que impidió que la sistemática violación de derechos humanos por parte de la dictadura franquista fuera investigada y que los responsables de dichas violaciones fueran enjuiciados. A esto se sumó la aprobación de la Ley de Patrimonio Documental que imposibilitaba, y aún imposibilita, el acceso a importantes fuentes documentales del franquismo, lo que supuso un gran obstáculo para el desarrollo de la labor de los investigadores, principalmente historiadores. En este contexto,

\footnotetext{
${ }^{2}$ Ley 46/1977, de 15 de octubre, de Amnistía. Boletín Oficial del Estado [en adelante, BOE], 17 de octubre de 1977. «http://www.boe.es/buscar/doc.php?id=BOE-A-1977-24937». [consultado el 10 de marzo de 2016].

${ }^{3}$ Ley 243/1979, de 10 de octubre, de Convenio Europeo de Derechos Humanos. BOE, 10 de octubre de 1979. «https://www.boe.es/buscar/doc.php?id=BOE-A-1979-24010». [consultado el 12 de marzo de 2016].

${ }^{4}$ Fouce, Guillermo, "Memoria Histórica y Derechos Humanos en España: balance de situación". «http:// www.2015ymas.org/centro-de-documentacion/publicaciones/2012/1341/memoria-historica-y-derechoshumanos-en-espana-balance-de-situacion/\#.V4d4NFdDWu6» [consultado el 14 de abril de 2016].

${ }^{5}$ Ley 52/2007, de 26 de diciembre, de Memoria Histórica. BOE, 27 de diciembre de 2007. «https://www.boe.es/ diario_boe/txt.php?id=BOE-A-2007-22296» [consultado el 10 de marzo de 2016].
} 
el gobierno consiguió hacer triunfar la "política del olvido" sobre el pasado traumático, lo que sin duda en un momento como es la transición, en el cual se estaba constituyendo el actual sistema democrático, significó una importante traba para la verdadera democratización del país, manteniendo así estructuras en el poder herederas de la dictadura, como por ejemplo puede ser la presencia de jueces provenientes del gobierno franquista dentro del sistema judicial.

Ante este desolador contexto político en torno a la recuperación de la memoria, cabe destacar que la interpretación crítica de la Guerra Civil y de la dictadura franquista recayó durante los primeros 20 años de transición de manera casi exclusiva en la figura de unos cuantos historiadores, los cuales comenzaron a investigar sobre el pasado oculto, abriendo así el debate sobre el tratamiento que otros países acometieron al superar un período de gobierno dictatorial. No obstante no será hasta mediados de los años 90, exactamente en el año 1996, cuando se marque el inicio simbólico de la recuperación de la memoria histórica al publicarse en el ámbito académico trabajos de gran calidad científica que aportarán nueva información sobre la guerra civil. Uno de los más significativos, señala Pedro Ruiz ${ }^{6}$, será el libro publicado por Paloma Aguilar, Memoria y Olvido de la Guerra Civil española, en el cual la autora denuncia el reparto de culpabilidad a la hora de hablar de la Guerra Civil y la política de olvido instaurada a partir del inicio de la transición.

El resurgir de esta revisión del pasado reciente trajo como consecuencia el nacimiento de dos movimientos sociales alrededor de este hecho; un primer movimiento estuvo constituido por las familias de las víctimas del franquismo en busca de conocer qué le había sucedido a sus parientes durante la Guerra Civil y/o la dictadura, y otro segundo movimiento estuvo formado por la prensa partidaria de ideas conservadoras y de derecha, quien retomó el estudio del pasado con el objetivo de divulgar la idea entre la sociedad de que la sublevación fascista del 1936 tuvo su principal motivo en poner fin al terror y desgobierno causados por el Frente Popular en el último gobierno de la Segunda República. No obstante, no cabe llevarse a engaños, pues a pesar de que el impacto de la labor reinterpretativa de los historiadores en torno a la Guerra Civil y la dictadura causó impacto dentro de la sociedad española, sus investigaciones, al menos la mayoría, se vieron limitadas por la falta de apoyo económico por parte de las universidades y por parte de las instituciones, teniendo así los historiadores que reducir su ámbito de estudio al ámbito local, acotando esto su labor a la producción de "un relato y recuento de las acciones violentas emprendidas por los militares sublevados en sus pueblos o en las comarcas más próximas"7. Por otra parte, aquellos historiadores que sí contaban con apoyo económico veían su labor supeditada a los intereses de quien los financiaba. Ya con el cambio de milenio, la

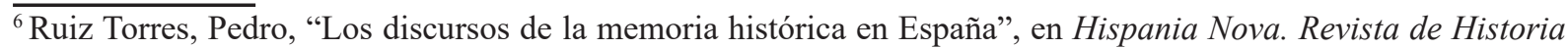
Contemporánea, 7 (2007), pp. 7-8. «http://hispanianova.rediris.es/7/dossier.htm» [consultado el 23 de marzo de 2016].

${ }^{7}$ Casanova, Julián "La historia social de los vencidos", en Cuadernos de Historia Contemporánea, 30 (2008), pp. 158-159. «http://revistas.ucm.es/index.php/chco/article/view/chco0808110155a» [consultado el 1 de abril de 2016).
} 
perspectiva para los historiadores mejorará, aunque no lo deseado ni lo suficiente. Esto se debe a un hecho fundamental como es exhumación en el año 2000 de los cuerpos de 13 republicanos asesinados durante el franquismo en la que se usó la técnica del ADN para identificarlos ${ }^{8}$, lo cual despertó un gran interés social por parte de las víctimas de familiares asesinados por el bando franquista por recuperar sus cuerpos, y a su vez esto despertó el interés por la labor de los historiadores, aumentando así en los últimos años muy notablemente los trabajos sobre la violencia ejercida sobre los vencidos, tema tabú durante muchos años dentro del ámbito académico.

Sin embargo, la mediatización de la recuperación de la memoria ha traído consigo la creación de un discurso histórico de tono conservador por parte de historiadores y prensa afín a la derecha ideológica. Destacando este discurso por mantener el mismo guión que el dado por el franquismo durante la dictadura, que no es otro que expandir la idea de que la sublevación franquista vino precedida de un gobierno republicano marcado por el descontrol político y social, como ya hemos mencionado anteriormente, y que la culpa por tanto del inicio y violencia de la Guerra Civil debe ser repartida a partes iguales entre los dos bandos participantes. Este discurso, gracias al apoyo de la prensa de derechas, ha calado y aún cala con fuerza en una importante parte de la sociedad, y sirve a la vez para legitimar la paralización del gobierno central en cuanto a la creación de políticas destinadas a revisar el pasado traumático y a reparar a las víctimas de la Guerra Civil y el franquismo. Ante este panorama, la historia crítica y objetiva tiene la responsabilidad de crear un discurso histórico, argumentado y fundamentado, que ponga fin a los arcaicos discursos que hacen "apología de la dictadura y del crimen organizado, como hacen todavía hoy conocidos periodistas, falsos historiadores y políticos de la derecha"9.

Por último, dentro aún del ámbito referente a la situación actual de la memoria histórica en España, debemos centrarnos en la situación de la misma dentro del ámbito de la educación, como principal preocupación de estudio para este artículo. Puesto que es la educación la mejor vía para la transmisión del conocimiento, y es por tanto el mejor medio para superar el desconocimiento de la sociedad española en cuanto a su pasado reciente. Sin embargo, el ámbito educativo no va a ser una excepción en el general anquilosamiento que vive España en referencia a la recuperación de la memoria; es más, la situación de la memoria histórica dentro de la educación nos ayuda a comprender claramente el porqué de la propia situación de la memoria histórica en otros ámbitos como pueden ser el social, el político o en el de la propia historia como disciplina científica. Un hecho fundamental para entender todo esto es la aprobación de la Ley Orgánica para la Mejora de la Calidad Educativa (LOMCE) en 2013

\footnotetext{
${ }_{8}^{8}$ Silva, Emilio, "Emilio Silva, hijo del fusilado que despertó la memoria", en El País, 6 de mayo de 2012. «http:// politica.elpais.com/politica/2013/05/06/actualidad/1367872450_767543.html» [consultado el 6 de mayo de 2012). 9 Casanova, Julián “¿Adiós al Franquismo?", en El País, 20 de diciembre de 2005. «http://elpais.com/ diario/2005/12/20/opinion/1135033207_850215.html» [consultado el 17 de febrero de 2016].
} 
y como ha afectado esto a la materia de historia ${ }^{10}$. Debido a que con la LOMCE el sistema educativo continúa a simplificar la enseñanza de la asignatura de historia, dirigiéndola a la mera memorización de conocimientos para superar una prueba y eliminando todo análisis crítico y al contraste de diferentes fuentes de información. Muestra de ello es la reducción del horario de historia en el último curso de la Educación Secundaria Obligatoria (ESO), algo que "choca" directamente con la amplitud del temario a tratar durante el curso que abarca desde el siglo XVIII hasta hoy en día, resultando realmente complicado poder abordar la totalidad del temario de manera correcta. Lo que trae como consecuencia directa, en palabras de Fernando Hernández Sánchez, que "muchos estudiantes estén abandonando la escolarización sin un conocimiento adecuado de las raíces de la sociedad en que se insertarán como ciudadanos activos"11.

En este mismo sentido, los manuales de la ESO para historia están estructurados de tal forma que dan a entender la historia reciente en base a los mitos que desde el franquismo se originaron de ella. Véase así como en dichos manuales está presente la idea de la culpabilidad de ambos bandos y la relación directa entre el período de la república y la Guerra Civil como fin inexorable; idea que surge a través de juntar ambos temas en una misma unidad. Por otra parte desde los manuales no se muestra conexión ninguna entra la guerra civil y el franquismo. A esto hay que añadirle que los libros se "olvidan" de tratar temas tales como el exilio, los maquis, los campos de concentración nazis, etc. Atendiendo a esto y siendo conscientes de la importancia que tienen los manuales en el proceso de enseñanza en el aula podemos comprender por qué la educación y conocimiento de la historia reciente está siendo tergiversado. Esta deformación de la realidad histórica aportada por los manuales sobre la Guerra Civil y el franquismo también se percibe en un importante número de profesores de historia de Educación Secundaria quien por miedo a no generar posibles ofensas entre los alumnos/as mantiene un discurso equidistante entre el papel tomado por el gobierno de la república y los sublevados; según se nos muestra a través de la tesis doctoral Profesores entre historia y memoria. Un estudio sobre la enseñanza de la dictadura-transición en España ${ }^{12}$. Esta desoladora situación unida al hecho de que muchas generaciones que estudiaron durante la dictadura y/o la transición no tuvieron la oportunidad de estudiar acerca de la Guerra Civil y la dictadura, al menos de manera objetiva y crítica, y que millones de personas no tuvieron la oportunidad ni siquiera de poder estudiar, hace que el desconocimiento a día de hoy sobre los hechos acontecidos durante la Guerra Civil y la dictadura sea aún tristemente notable. Es por tanto labor fundamental de la educación recuperar el pasado traumático oculto con el fin de transmitirlo de generación en generación y evitar que

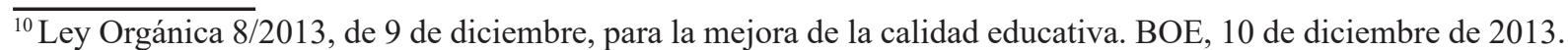
«https://www.boe.es/diario boe/txt.php?id=BOE-A-2013-12886, 2013» [consultado el 22 de abril de 2016].

${ }^{11}$ Hernández Sánchez, Fernando, "El Franquismo en la ESO”, en Público, 3 de junio de 2011. «http://blogs. publico.es/dominiopublico/3474/el-franquismo-en-la-eso/» [consultado el 16 de febrero de 2016].

${ }_{12}$ Martínez Rodríguez, Rosendo, Profesores entre historia y memoria. Un estudio sobre la enseñanza de la dictadura-transición en España, tesis doctoral, Universidad de Valladolid, 2013.
} 
nunca más se olvide, pues esto servirá a la vez para trasmitir los necesarios valores democráticos que ayuden a las nuevas generaciones a formar una sociedad totalmente libre y tolerante.

\section{Los procesos de recuperación de la memoria histórica en otros países}

Una vez revisada la situación actual de la memoria histórica en España, es necesario hacer referencia a otros procesos de recuperación del pasado traumático tras un período dictatorial para entender mediante la comparación que factores impiden hablar de una verdadera reparación de este pasado traumático en España y por el contrario permiten destacar positivamente la labor desempeñada en otros países, como en este caso son Alemania, Argentina o Chile. El primer proceso de recuperación de la memoria que trataremos será Alemania por razones evidentes; al ser el caso alemán el más significativo, tanto por el número de víctimas como por la repercusión que el Tercer Reich tuvo a nivel mundial. Un primer acto significativo serán los juicios de Núremberg de 1945 a 1948, donde los principales dirigentes nazis tuvieron que responder ante un tribunal por los crímenes cometidos contra la humanidad. No obstante, no podremos hablar de recuperación de la memoria histórica hasta finales de los años 60 , pues será en esa época bajo el amparo de las nuevas generaciones universitarias y con la llegada al cargo de canciller de la República Federal de Alemania (RFA), más conocida como Alemania Occidental, de Willy Brandt, cuando se comience a promover la revisión crítica del pasado. Será en la propia década de los 60 cuando se levanten los primeros monumentos conmemorativos en honor a las víctimas del nazismo en la Alemania Occidental, no sin estar exento de conflicto, debido a la fuerte oposición de ciertos sectores políticos y sociales contrarios a revivir el pasado traumático a través de la conmemoración de las víctimas ${ }^{13}$. A pesar de ello, esta oposición no consiguió impedir que se levantaran en Alemania monumentos con tal significación hoy día como son El Museo Judío, inaugurado en 1999, y que representa un centro educativo sobre la cultura judía en Alemania, y el Monumento en Memoria de los Judíos Asesinados de Europa, inaugurado en 2005. A su vez, desde los años 50, la RFA comenzará a pagar reparaciones por los crímenes cometidos, siendo Israel el primer país en recibir compensaciones económicas. Será en la década de los 80 , tras la realización, desde los años 60 , de las primeras investigaciones exhaustivas sobre el nazismo, cuando surja la polémica entre historiadores sobre la interpretación del nazismo, al acusar Jürgen Habermas, filósofo, a Ernst Nolte, historiador, de relativizar los crímenes nazis ${ }^{14}$; hecho significativo de que el proceso de la recuperación en Alemania nunca fue una labor sencilla. Por

\footnotetext{
${ }^{13}$ Frey, Peter, "Cultura de la Memoria en Alemania", conferencia impartida en la Universidad Nacional de Bogotá, 2 de octubre de 2014.

${ }^{14}$ Rauschenberg, Nicholas, "El problema de la normalización en tres debates: Historización, Historikerstreit y Goldhagen", en Anos 90, 23 (2016), pp. 443-487.
} 
otro lado, la República Democrática Alemana (RDA), Alemania Oriental, afrontó el nazismo desde una perspectiva diferente; la expurgación de los nazis de los puestos de responsabilidad pública, tras el fin de la Segunda Guerra Mundial, fue más eficaz que en la RFA; en gran parte, debido a que las penas ejecutadas contra los acusados de pertenecer al régimen nazi fueron mucho más severas. La RDA, a su vez, también pagó compensaciones económicas por los crímenes nazis a otros países, si bien es cierto que los principales beneficiados de estas compensaciones fueron Polonia y la Unión Soviética. Ya a partir de 1989, con la caída del Muro de Berlín, el derrumbamiento del bloque socialista y la reunificación de Alemania, la política de memoria llevada a cabo hasta ese momento en la Alemania Occidental se aplicará también en la antigua Alemania Oriental, destacando entre los muchos acontecimientos que tuvieron lugar a favor de la recuperación del pasado, la aprobación de la Ley sobre los archivos de la Stasi (servicio de inteligencia de la antigua RDA) en 1991, que concedía el derecho de los ciudadanos a consultar los expedientes realizados por la Stasi en el tiempo que duró la $\mathrm{RDA}^{15}$. Podemos entonces concluir para el caso alemán, que no siendo sencillo el proceso de enfrentamiento con el pasado, el fuerte sistema democrático que ha conseguido levantar, nos muestra que las políticas de memoria tienen resultados muy positivos.

Una vez analizado el caso alemán, es necesario centrar nuestra visión en dos casos como son el caso argentino y el caso chileno, por encontrarse ambos muy unidos histórica y culturalmente a España. Sin embargo, estos dos países han sufrido procesos dictatoriales más recientemente que España y a pesar de ello han conseguido aplicar una política de reparación del pasado traumático mucho más efectiva y ambiciosa que la española, que es, por otra parte, casi nula. El primer caso dentro del ámbito latinoamericano que abordaremos será Argentina. El proceso de reparación del pasado traumático y de recuperación de la memoria en Argentina, al final de la dictadura cívico-militar en 1983, tiene su inicio con la creación de la Comisión Nacional sobre la Desaparición de Personas (CONADEP), por parte del gobierno de Raúl Alfonsín, con el objetivo de investigar sobre los crímenes contra los Derechos Humanos durante la dictadura. Posteriormente, en 1985, se llevará a juicio a las Juntas Militares que dirigían el país desde el golpe militar de 1976, siendo condenados cinco de los nueve comandantes acusados ${ }^{16}$. Sin embargo, esta política de memoria se verá frenada debido a la fuerte presión que ejercen las Fuerzas Armadas y la iglesia, contrarias a la recuperación del pasado, sobre el gobierno de Alfonsín y que se traducirá en la aprobación de las leyes de Punto Final y Obediencia Debida, entre 1986 y 1987, lo cual supondrá la paralización de las causas penales contra los supuestos culpables. A su vez, esto traerá la indignación de una amplia parte de la sociedad, la cual desde el inicio de la transición destacará por su enorme apoyo a la recuperación de la memoria a través de la creación de diferentes movimientos sociales, donde destacan especialmente Las Madres

\footnotetext{
${ }^{15}$ Frey, Peter, "Cultura de la memoria..." op. cit.

${ }^{16}$ Bolaños de Miguel, Manuel, "Políticas de la memoria, lucha contra la impunidad y derechos humanos en Argentina post dictadura". «https:/www.ucm.es/data/cont/docs/297-2013-07-29-3-08.pdf» [consultado el 4 de noviembre de 2016].
} 
de Plaza de Mayo, quienes se dedicarán a la busca de los niños/as desaparecidos-secuestrados durante la dictadura y entregados a otras familias. El proceso de reparación del pasado se detendrá totalmente cuando entre en el gobierno Carlos Menem, durante el cual se llevarán a cabo una serie de indultos a los militares de la dictadura y a la vez se tratará de zanjar la política de recuperación de la memoria de manera definitiva, a pesar de la fuerte oposición social con la que contó durante su mandato. Ya en 2003 se recuperarán las políticas destinadas a reparar a las víctimas de la dictadura cuando Néstor Kirchner se convierta en presidente. Kirchner se apoyará en la vía política para aplicar la vía judicial en contra de las "políticas del perdón y del olvido" ejecutada por parte de los anteriores gobiernos. Para ello retirará a los comandantes militares pertenecientes a la dictadura del ejército, cambiará a todos los jueces de la Corte Suprema, relacionados con las políticas del olvido y perdón, por jueces de corte progresista y otorgará al Poder Judicial la capacidad de revisar uno por uno los casos de extradición o no de militares argentinos vinculados con la represión durante el gobierno dictatorial. Centrará también su política en acabar con las leyes de la impunidad, de esta forma la Corte se encargó de anular las leyes del perdón y el olvido a través de la creación de la Unidad de Asistencia para Causas de Violaciones de Derechos Humanos y a la vez se anularon los indultos dados en el Gobierno de Menem, más de manera simbólica que numérica pero sirvió para establecer que el sistema jurídico persiguiera el olvido y la impunidad contra los responsables de delitos contra la humanidad ${ }^{17}$. Ya centrados exclusivamente en la vía política, destacar que Kirchner creará el Archivo Nacional de la Memoria, mediante el cual levantó el secreto militar y lo puso a disposición del Archivo Nacional, y también creará el Museo de la Memoria en un lugar emblemático de la dictadura. Todo ello nos permite entender por qué en el año 2010 la memoria histórica argentina fue ensalzada por la ONU al ser el país "con mayor número de juicios por derechos humanos del mundo"18.

El último ejemplo de proceso de recuperación de la memoria histórica es Chile; donde la memoria social del país está fuertemente asociada al golpe militar y a la posterior dictadura regida por Augusto Pinochet, que va de 1973 a 1990, por estar marcados estos hechos por una clara situación traumática que dejará huella en muchas generaciones de chilenos, incluyendo a los que no vivieron este período ${ }^{19}$. Este proceso de recuperación de la memoria comenzará en los primeros años de la dictadura de la mano de la Iglesia y de los movimientos sociales, donde destaca entre otros la Agrupación de Familiares de Detenidos Desaparecidos (AFDD), cuya labor se centrará en la defensa de los derechos humanos y, especialmente, en la reconstrucción de las memorias de la dictadura. Una vez finalizada la dictadura, ante la falta de apoyos

\footnotetext{
${ }^{17}$ Ibídem.

18 “Elogio de la ONU por los juicios a represores", en Página 12, 6 de agosto de 2012. «http://www.pagina12.com. ar/diario/ultimas/20-150875-2010-08-06.html» [consultado el 2 de febrero de 2016].

${ }^{19}$ Guichard, Eduard y Guillermo Henríquez, "Memoria histórica en Chile: una perspectiva intergeneracional desde Concepción", en Revista Española de Investigaciones Sociológicas, 135 (2011), pp. 20-21. DOI: http://dx.doi. org/10.5477/cis/reis.135.3.
} 
políticos y sociales, Pinochet cederá su poder al partido democristiano en 1990, y será en ese momento cuando el presidente Aylwin convoque a la Comisión Nacional de Reparación y Reconciliación y se publique el informe Rettig, donde se documentarán las desapariciones con muerte de chilenos durante la dictadura, pero que destacará negativamente por no nombrar ni enjuiciar a las responsables de estas desapariciones. Sin embargo, los movimientos sociales y el Partido comunista no cesarán en su lucha y presionarán al Estado, consiguiendo, con la ayuda de abogados especialistas en derechos humanos, encontrar los resquicios legales de la Ley de Amnistía de 1978 para así iniciar las primeras causas judiciales contra militares, siendo la detención de Pinochet en 1998 la más notable consecuencia de esta lucha ${ }^{20}$. Ya en 2005, coincidiendo con el bicentenario de Chile, se publica el informe Valech por parte de la Comisión Nacional sobre Prisión Política y Tortura en Chile donde, a diferencia del informe Rettig, se reconocen los actos contra la humanidad llevados a cabo durante la dictadura, pero no supone, nuevamente, ninguna consecuencia judicial para los culpables de esos delitos, triunfando así de este modo la impunidad. Por último destacar en este proceso de recuperación de la memoria, el papel de los memoriales, los cuales abundan por todo el país, y ayudan a establecer lugares físicos para la memoria. Muchos de estos memoriales se mantienen hoy en pie gracias a la pugna de los movimientos sociales contra el Estado, evitando que este último vendiera o destruyera terrenos con gran significación en la dictadura. En esta política de construcción de memoriales destacan, entre otros muchos, el cambio de nombre de Estadio Chile a Estadio Víctor Jara, la conversión de la Villa Grimaldi, centro de torturas y asesinatos, en el Parque de la Paz, primer memorial de Latinoamérica erigido sobre un centro de torturas, y por supuesto la creación del Museo de la Memoria y los Derechos Humanos. Siendo conocedores de ello, podemos concluir que la memoria histórica en Chile, a pesar de la impunidad de los culpables, es muy positiva pues se ha conseguido exitosamente rescatar la historia ocultada y se mantiene una política de reparación de las víctimas muy fuerte.

\section{La labor de los museos memoriales en Alemania, Argentina y Chile}

Sin abandonar los procesos de revisión crítica del pasado traumático de estos tres países, es necesario centrarnos ahora en los principales museos construidos por Alemania, Argentina y Chile en torno a la recuperación de la memoria, por la importante labor educativa que han desempeñado y desempeñan aún hoy en día en la concienciación de la sociedad sobre la

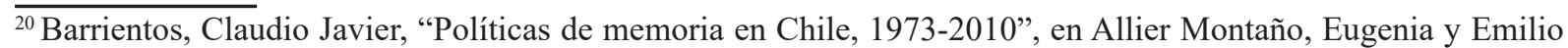
Crenzel (coords.), Las luchas por la memoria en América Latina. Historia reciente y memoria politica, Ciudad de México, Universidad Nacional Autónoma de México, 2015, pp. 95-122.
} 
importancia de los sucesos ocurridos durante los procesos dictatoriales y la necesidad de aprender de ellos, resultando hoy en día un pilar fundamental para afrontar una interpretación exitosa del pasado. En el ámbito museístico Alemania tampoco descuidará la labor educativa sobre lo acontecido durante el holocausto nazi, siendo numerosos los museos creados en territorio alemán destinados a dar a conocer desde una visión cultural pero, por supuesto, también didáctica de este período concreto. Siendo imposible reunir en un solo artículo el trabajo desempeñado por todos estos museos, analizaremos uno de los más simbólicos, el Centro de Documentación del Nacionalsocialismo, por la enorme transcendencia que tiene dentro y fuera de la sociedad alemana. Este museo será construido en 2002 en Munich sobre la primera sede del NSDAP, el partido político nazi, conocedores de las torturas allí cometidas y siendo conscientes de deuda histórica que dicho edificio mantiene con la sociedad alemana; atendiendo a esto erige un lugar memorial con la intención de visibilizar los horrores del nazismo y concienciar a la sociedad de la consecuencia que dichos actos, las atrocidades cometidas desde el bando nazi, tienen en la actualidad. Representa por tanto este edificio actualmente, un centro abierto a la reflexión y a la discusión de este determinado período histórico, a la vez que estudia este pasado traumático y lo conecta con el presente desde una perspectiva educativa. El centro se compone de una exhibición permanente, Munich y el nacionalsocialismo que a través de documentos, imágenes y objetos nos explica el papel de Munich en el nacionalsocialismo y los actos allí ocurridos Esta se divide en 4 épocas que abarcan desde el fin de la Primera Guerra Mundial al fin de la Segunda Guerra Mundial. También cuenta con un catálogo que presenta una gran colección de materiales de grandes autores sobre Munich y su papel en el nazismo. Pero lo más destacable por el enorme trabajo que realizan en este campo desde el museo y, por supuesto, por el valor mismo de la actividad que allí desempeñan es el Departamento de Educación, el cual ahondará en la reflexión crítica de este período, poniendo al alcance de todos, una base de datos, entrevistas audiovisuales y una biblioteca especializada sobre esta etapa. Ya para los alumnos de escuelas y/o institutos se ofrecen programas educativos especiales a través de seminarios. Siendo de este modo la labor educativa del Centro de Documentación del Nacionalsocialismo, llevada a cabo desde una perspectiva histórico-política que pretende concienciar a los visitantes de la importancia de los valores democráticos a través de los horrores del pasado, para así poder aplicar dichos valores en el presente.

En Argentina el museo más emblemático en el ámbito de la memoria histórica es el Museo de la Memoria, en Buenos Aires. Dicho museo será fundado en 1998 con el objetivo de dar uso a diferente material histórico para poner en conocimiento de la sociedad las violaciones de derechos humanos ocurridas en la dictadura. Este será construido sobre una antigua sede del ejército durante la dictadura y destacará por ser uno de los museos pioneros en Latinoamérica en su función de memorial de un pasado traumático. El museo consta de los siguientes departamentos: la biblioteca, con todo tipo de material ofertado al público para conocer desde 
distintas disciplinas científicas, tales como la historia o el derecho, lo ocurrido en la dictadura en materia de derechos humanos; el departamento de jóvenes y memoria, en el cual se llevan a cabo distintas actividades con jóvenes para el entendimiento de la historia del presente a través de la historia del pasado; el Departamento Bosque de la Memoria, que es un homenaje a las víctimas de la dictadura a través de la plantación de árboles en fechas significativas; el departamento Centro Documental Rubén Naranjo, el cual se encarga de la recopilación y cuidado, y posterior exposición de diferentes documentos y otro tipo de material perteneciente a la época de la dictadura, véanse los testimonios de gente torturada o las narraciones sobre desaparecidos; el Centro de Estudios de Historia Reciente de Argentina y Latinoamérica, donde se llevan a cabo estudios e investigaciones sobre diferentes acontecimientos y/o relatos sobre la dictadura para proyectarlos desde la perspectiva científica de la historia; y por último, y más importante en lo que a la temática de este artículo se refiere, el departamento de educación, el cual tiene como principales metas promover la reflexión crítica sobre el período dictatorial, concienciar sobre la importancia de valores democráticos tales como la justicia o la libertad $\mathrm{y}$ dar en conocimiento la constante violación de derechos humanos que aún tiene lugar en el presente, al igual que sucedía durante la dictadura.

Por su parte, el museo más significativo en la labor de recuperación del pasado traumático en Chile es el Museo de la Memoria y los Derechos Humanos. Este será inaugurado en 2010 en un barrio muy simbólico de Santiago de Chile, la avenida Matucana, pues durante la dictadura se cometieron muchas violaciones por parte del ejército en esta zona. El museo será construido con el objetivo de reflexionar sobre los hechos acontecidos durante la dictadura de Pinochet y también con el fin de honrar a las víctimas. El museo memorial chileno busca proteger el patrimonio documental sobre este período en concreto, llevar a cabo una labor de educación y reflexión sobre lo acontecido, y a la vez ser un eje de comunicación que sirva para exponer y recibir todo asunto y/o hecho de relevancia relacionado con la memoria histórica y los derechos humanos. El museo cuenta con un centro de documentación cuyos fondos documentales han sido declarados por la Unesco, parte del Programa Memoria del Mundo ${ }^{21}$.

Este centro de documentación está constituido por un centro de documentación audiovisual, una biblioteca digital, un archivo digital y un catálogo online, con material sobre la dictadura y la concienciación en materia de derechos humanos. Por último, destacar el departamento de Educación que basará su labor en la promoción de los valores democráticos, en la memoria y el respeto a los derechos humanos. Para ello llevará a cabo talleres y cursos para todo tipo de público, y actividades específicas para concienciar a los niños en el respeto por los derechos humanos desde muy pequeños; a la vez que empleará el material educativo oportuno para ayudar a la comprensión de los vínculos existentes entre el pasado traumático y el presente que se vive.

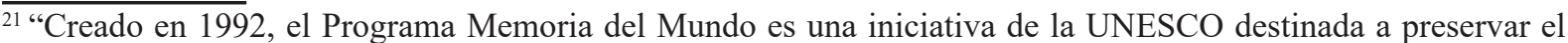
patrimonio documental del mundo como símbolo de la memoria colectiva de la humanidad". Extracto publicado por la Unesco en «http://www.unesco.org/new/es/santiago/communication-information/memory-of-the-worldprogramme-preservation-of-documentary-heritage/» [consultado el 16 de octubre de 2016].
} 
Este mismo trabajo educativo lo desarrollarán también otros museos de gran importancia en la reparación de pasados traumáticos como pueden ser el Yad Vashem en Israel, el Memorial de Terezín en la República Checa, o el Museo de la Resistencia y la Deportación de Besançon en Francia, entre otros. Serán estos museos, sin duda alguna, un gran referente en la recuperación de la memoria histórica para aquellos países que han sufrido las crueldades acometidas durante períodos dictatoriales por su capacidad de permitir a la sociedad mantener un contacto directo y de aprendizaje con la historia oculta.

\section{Análisis crítico acerca de la situación de la memoria histórica en España en el} ámbito cultural y educativo y propuestas para un cambio de la situación

De nuevo y ante este contexto internacional que acabamos de analizar sobre la reparación del pasado traumático, tenemos que volver a hablar de inactividad, no total pero significativa, cuando nos referimos a la labor cultural y educativa llevada a cabo por España en materia de memoria histórica.

Dicha inactividad está marcada, principalmente, por el desinterés del gobierno central por impulsar una verdadera política cultural en torno al establecimiento de una interpretación universalmente aceptada de la Guerra Civil y del franquismo, lo que tiene como consecuencia que dicha política cultural recaiga en la voluntad de iniciativas privadas o de gobiernos locales, con los límites económicos y de medios que conlleva eso. Entre esta limitada actividad cultural, podemos, y debemos, destacar algunos de los principales actos por la memoria como son las recreaciones de batallas trascendentales de la Guerra Civil como la batalla del Jarama o del Ebro. Estas recreaciones consisten en la caracterización y escenificación de los hechos históricos acontecidos durante los combates en los mismos emplazamientos donde tuvieron lugar casi 80 años atrás. En esta misma zona se organizarán marchas memoriales como la Marcha Memorial del Jarama, la cual se celebra anualmente y se fundamenta en una ruta a pie por los lugares más emblemáticos de la batalla, durante dicha marcha un guía explicará los hechos allí ocurridos durante la guerra y a la vez se aprovechará para homenajear a las diferentes brigadas internacionales que vinieron a España a combatir la sublevación fascista. Un hecho que puede ser representativo de la situación de la memoria en España, desde una perspectiva cultural, es la existencia de un único museo dedicado a la Guerra Civil ${ }^{22}$, en Morata de Tajuña (Madrid), el cual está situado dentro de un bar, y se trata obviamente de un proyecto

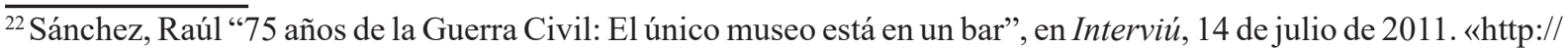
www.interviu.es/reportajes/articulos/75-anos-de-la-guerra-civil-el-unico-museo-esta-en-un-bar» [consultado el 15 de marzo de 2016].
} 
privado. Son así estos actos a excepción del museo madrileño, actos culturales marcados por su temporalidad, se celebran durante un día o dos al año, lo que hace que su labor se vea fuertemente limitada por no disponer de una sede fija que les permita dejar de ser meras representaciones ocasionales y poder llegar así a más gente. En esta misma línea, el hecho de que se hable de actos locales limita enormemente el público al que se transmite el mensaje. La falta de medios y apoyo de la administración pública es también un fuerte obstáculo a la transcendencia social que puedan alcanzar dichos actos tanto a nivel nacional como internacional, hecho que afecta sobre todo al museo de la Guerra Civil. Por su parte, en lo referente al ámbito educativo, a pesar del rígido guión histórico bajo el que se organizan estos eventos culturales, el enfoque pedagógico queda muchas veces minusvalorado ante el homenaje y la recreación fidedigna de lo allí sucedido. Ninguno de estos aspectos puede desvalorizar la importancia y necesidad de la existencia de dichos actos, los cuales suponen un foco de resistencia ante la desmemoria que desde las administraciones centrales se pretende imponer a la sociedad española ante nuestro pasado reciente; no obstante, debemos seguir exigiendo y luchando por la existencia de una política pública de recuperación de la memoria histórica seria y eficaz donde, por supuesto, la educación y los museos deben jugar un papel fundamental.

Ante este contexto político, social y cultural que hemos venido analizando a lo largo del artículo en torno a la revisión crítica del pasado reciente y ante el hecho, de que cuarenta años después del fin del régimen franquista sigue reinando la idea de que la dictadura no fue tan negativa como la historiografía afirma y que ambos bandos tuvieron igualdad de culpa en el comienzo de la Guerra Civil y posterior represión, podemos afirmar que la memoria histórica ha fallado estrepitosamente en España ${ }^{23}$. Esto no se debe únicamente a la falta de políticas efectivas que se dediquen a la reparación del pasado traumático, sino que también tiene su razón de ser en la inexistencia en España de una educación crítica con el discurso oficial que tenga la capacidad de llegar a la mayoría de la sociedad; es decir, sí que existen, afortunadamente, en España los historiadores capaces de desmontar los mitos que aún persisten dentro de la población española sobre la Guerra Civil y el franquismo, tales como la dualidad de la culpa en la guerra o la "supuesta" ausencia de represión en los últimos años de la dictadura, lo que no existen son los organismos culturales y educativos capaces de generar un conocimiento crítico y verídico en la mayoría de la sociedad sobre este pasado reciente. Y esto se debe, como ya hemos mencionado anteriormente, al triunfo de un discurso basado en la idea de evitar "reabrir viejas heridas", sobre el que se ha construido nuestra democracia y que el sistema político actual defiende, y es secundado desde la prensa más conservadora. Este discurso ha calado entre la sociedad y ha causado el desinterés de la misma por nuestro pasado reciente y a la vez la aceptación de las tesis históricas que desde estos mismos medios de derechas se proclaman y en los que se hace

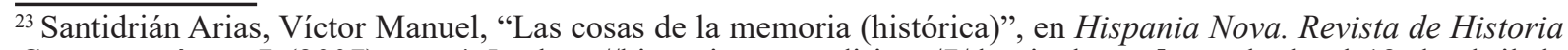
Contemporánea, 7 (2007), pp. 4-5. «http://hispanianova.rediris.es/7/dossier.htm» [consultado el 12 de abril de 2016].
} 
un análisis poco crítico con el bando sublevado y nada fiel a la realidad de los sucesos ocurridos durante la Guerra Civil y la dictadura.

La ignorancia de una gran parte de la sociedad española acerca de un período tan reciente y trascendental para nuestro presente como son la Guerra Civil y el franquismo hace que no podamos hablar de una democracia totalmente sana, ya que no se ha permitido a la población la comprensión de los sucesos ocurridos durante la dictadura y la necesidad de defender todos y cada unos de los valores que un sistema democrático debe proteger. Ante este contexto, es necesario echar mano de la educación para poner fin a este desconocimiento, pero siendo conscientes por supuesto de la falta de amparo por parte de la administración pública a toda educación que plantee una reinterpretación crítica del pasado traumático; es aquí donde juega un papel fundamental la figura del museo memorial como el organismo educativo más apto para difundir un correcto conocimiento y comprensión del pasado a público de cualquier edad, procedencia social y/o cultural, y a la vez obviar el discurso oficial, al que anteriormente hacíamos alusión, que desde la educación se imparte a los jóvenes. Por ello, no solo desde la historia, sino también desde el campo de la educación y desde el campo de la justicia, se debe luchar por la creación de un museo memorial en España, de iniciativa privada mientras desde el gobierno se obstaculice la vía pública, para comenzar a erradicar la desmemoria que predomina en la sociedad española, y sobre todo en las generaciones más jóvenes.

La elección del museo memorial, desde este artículo, como educador de nuestra sociedad no es un hecho casual sino que se hace desde la consciencia de la idoneidad del mismo para desempeñar dicha labor. Esto es debido, desde una primera perspectiva, a que la educación en los museos de la memoria es llevada a cabo a través de la historia, como disciplina científica, la cual ha sido un referente formativo a lo largo de los últimos siglos, sobre todo; véase como tanto en el siglo xIX como en el siglo xx se instruía a la sociedad en valores dominantes, como bien podían ser los ideales nacionalistas ${ }^{24}$. Siendo, es cierto, utilizada en este caso la educación en historia para crear "súbditos a las necesidades de la patria" y no "ciudadanos y ciudadanas libres" 25 . No obstante, la historia como educadora social, no tiene solo la capacidad de instruir a la población bajo los intereses de la clase dominadora, sino que tiene la competencia a la vez de formar seres críticos con la sociedad en la que viven y al mismo tiempo poseedores de una visión analítica que les permita adaptarse al mundo en el que viven y asimismo encontrar soluciones y/o alternativas a los diferentes problemas sociales que se les presenten. Esto lo consigue la educación en historia a través de la historia comparada, que es aquella que "aspira a reconstruir la realidad pasada desde perspectivas presentes, que a su vez, están relacionadas con

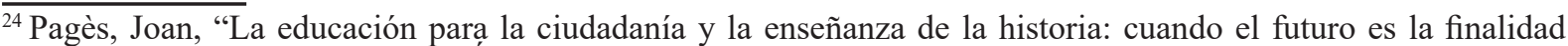
de la enseñanza del pasado", en Ávila Ruíz, Rosa María et al. (coords.), Las competencias profesionales para la enseñanza-aprendizaje de las Ciencias Sociales ante el reto europeo y la globalización, Bilbao, Asociación Universitaria de Profesores de Didáctica de las Ciencias Sociales, 2007, pp. 205-206.

${ }^{25}$ Ibídem, pp. 205-206.
} 
expectativas de futuro"26. La comparación histórica nos sirve entonces para comprender nuestro presente al vincularlo directamente a un pasado concreto, y esta comprensión del presente es la que nos ayuda a discernir el futuro y las necesidades o no de cambio de este por parte de la sociedad. Lo que pretende por tanto con la aplicación de la historia comparada es dar un conocimiento profundo de los hechos ocurridos años atrás para "utilizar este conocimiento para comprender mejor el mundo" en que vivimos e impedir que se vuelvan a suceder los errores cometidos en el pasado ${ }^{27}$. No perdiendo nunca de vista la perspectiva de los museos memoriales, debemos señalar que la historia es la disciplina ideal para la enseñanza de Derechos Humanos, algo totalmente imprescindible cuando se habla de pasados traumáticos, pues esta nos ayuda a entender todos aquellos procesos tanto a nivel mundial como nacional que sirvieron para lograr la paz y desarrollar los valores democráticos, así como aquellos que significaron para el deterioro del mismo; consiguiendo así concienciar a la sociedad en la importancia que supone la defensa de ideales de tolerancia y respeto y a la vez tomen percepción de la enorme responsabilidad que cada uno tenemos en la construcción de una sociedad totalmente demócrata ${ }^{28}$.

Por otro lado, la idoneidad y necesidad del museo memorial para afrontar la memoria histórica en España no puede ser entendida sin analizar la figura en sí del museo y las características que lo hacen hoy en día uno de los organismos educativos más eficientes. El museo ha abandonado en los últimos años su papel tradicional de mero expositor cultural para convertirse ahora en un centro de debate e interacción social al llevar a la sociedad cuestiones de interés para ella ${ }^{29}$. Este cambio en la figura del museo se produce a partir de los años 80 del siglo pasado, asociado a un movimiento conocido como "nueva museología" que otorga ahora al museo el papel no solo de educador sino también de actor social, en lo que a la adopción de medidas sobre cuestiones sociales importantes se refiere ${ }^{30}$. El museo desempeña en la "nueva museología" una clara labor de educador social al convertirse en no un simple complemento de la educación formal, sino que llega a esos espacios de la ciudadanía que ya están fuera del sistema educativo, aportándole el museo los valores cívicos y culturales que desde la prensa o la propia sociedad no se enseñan ${ }^{31}$. Dentro de esta "nueva museología” los museos de historia no son una excepción, alejándose a partir la segunda mitad del siglo xx de su papel tradicional como colectores de objetos del pasado y centrándose ahora en las personas y en los cambios sociales,

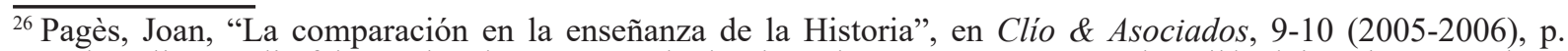
18. «http://www.clio.fahce.unlp.edu.ar» [consultado el 10 de mayo 2016]. DOI: http://dx.doi.org/10.14409/cya. v1i9/10.1608.

${ }^{27}$ Ibidem, p. 31.

${ }^{28}$ Siede, Isabelino, "El aporte de las Ciencias Sociales a la Educación en la Paz y los Derechos Humanos", en Revista de Teoría y Didáctica de las Ciencias Sociales, 3 (1998), p. 181. «http://www.saber.ula.ve/gitdcs/» [consultado el 3 de mayo de 2016].

${ }^{29}$ Svanberg, Fredrik, "Towards the museum as forum and actor?", en Svanberg, Fredrik (coord.), The museum as forum and actor, Estocolmo, Statens Historiska Museum, 2010, pp. 16-17.

${ }^{30}$ Ibídem, pp. 16-17.

${ }^{31}$ Arbúes, Elena y Concepción Naval, "Los museos como espacios sociales de educación”, en Estudios sobre Educación, 27 (2014), pp. 133-155. DOI: http://dx.doi.org/10.15581/004.27.133-151.
} 
siendo de ese cambio de donde nacen los museos memoriales ${ }^{32}$. Los museos memoriales desde su origen van a desarrollar un importante papel de actor social, puesto que al "enfrentar el pasado conflictivo es un componente esencial de la construcción de una identidad nacional basada en los derechos y la dignidad humana, y por tanto la construcción de estos escenarios son un aporte significativo a la reconstrucción de una sociedad devastada" 33 .

Responderán así a las demandas sociales de las víctimas de procesos dictatoriales que encontrarán en estos organismos el medio de reparar la memoria de sus antepasados o de ellos mismos, pero a la vez dichos museos servirán como foco de resistencia a la impunidad de los culpables. Deben entonces los museos memoriales con el fin de cumplir la función social para la que fueron pensados, mantener una visión crítica y de denuncia con los culpables a la vez que se apoya a las víctimas ${ }^{34}$, y al mismo tiempo dar un uso efectivo a la educación en historia, mostrando una interpretación crítica y objetiva del pasado mientras se conciencia al público asistente de la importancia que tiene no olvidar el pasado traumático y aprender de él para mejorar nuestro presente pero sobre todo para construir un futuro mejor. Siendo entonces conscientes de la trascendental labor que desarrollan los museos memoriales en el ámbito educativo de una sociedad que ha sufrido un pasado traumático, solo nos podemos preguntar ¿por qué en España no tenemos un museo de la memoria?

\section{Conclusiones}

Como hemos podido ver, a diferencia de países como Alemania, Argentina o Chile, España no ha sabido, por falta de interés desde el gobierno central, asentar una interpretación universalmente aceptada de su pasado traumático. De este modo a día de hoy, el desconocimiento sobre nuestro pasado y las tergiversaciones sobre el mismo aún son muy notorias dentro de la sociedad española; a esto se suma la falta de reparación a las víctimas, siendo aún miles las personas que tienen a algún familiar desaparecido a causa de la represión del franquismo. En el ámbito de la justicia, como no especialista pero sí ciudadano, debo reclamar que a través del poder judicial se ponga fin a los obstáculos que impiden honrar la memoria de las víctimas, a la vez que reparar los daños causados a las víctimas y a sus familiares por parte del bando franquista, e investigar íntegramente la realidad de lo sucedido; véase entre estos impedimentos judiciales la propia Ley de Amnistía de 1977. En el ámbito de la educación, no solo como

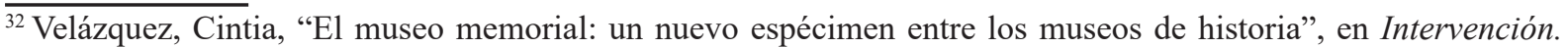
Revista Internacional de Conservación, Restauración y Museología, 3 (2011), pp. 26-27.

${ }^{33}$ Mora, Yaneth, "Lugares de la memoria: entre la tensión, la participación y la reflexión", en Panorama, 7 (2013), pp. 99-101. DOI: http://dx.doi.org/10.15765/pnrm.v7i13.434.

${ }^{34}$ Velázquez, Cintia, "El museo memorial..." op. cit., p. 28.
} 
ciudadano sino también como historiador especializado en la rama educativa, debo demandar la potenciación y mejora de la enseñanza que desde inicios de la democracia, en 1978, se lleva transmitiendo a generaciones y generaciones de españoles, y que claramente no ha conseguido aportar un conocimiento profundo sobre una etapa de nuestra historia que nos afecta tan directamente. Es por tanto intención de este artículo mostrar la necesidad de la creación de un museo memorial en España, aunque en su origen se cree desde el ámbito privado, que se una, en colaboración, a los actos culturales a favor de la memoria ya existentes, no solo con la finalidad de aportar saber a la sociedad española sobre la Guerra Civil y la dictadura, sino también para concienciar a la sociedad española del deber que tenemos con nuestro pasado y con su revisión crítica, y que esto ayude a crear el impulso social que se necesita para modificar todas aquellas políticas y leyes que nos impiden reexaminar nuestro pasado con el objetivo de avanzar cara el futuro con paso firme de una vez por todas. 